\title{
The Phospholipids of Corynebacteria
}

PATRICK J. BRENNAN and DEREK P. LEHANE, ${ }^{1}$ Department

of Biochemistry, Trinity College, Dublin 2, Ireland

\section{ABSTRACT}

The phospholipids of Corynebacterium diphtheriae, Corynebacterium xerosis, Corynebacterium equi and Corynebacterium ovis were examined, largely by chromatographic procedures. In all of these, lipids of the phosphoinositide and mannophosphoinositide type were prominent. In contrast to the mycobacteria, the mannophosphoinositides of the corynebacteria were all dimannophosphoinositides; however, as in mycobacteria, these dimannophosphoinositides apparently occurred in the diacylated and triacylated forms-the tetraacylated component prominent in mycobacteria was absent. Phosphatidylethanolamine and phosphatidylserine were also absent. In Corynebacterium diphtheriae the major single phospholipid corresponded to phosphatidylglycerol: cardiolipin also appeared to be a major lipid. The fatty acids of the corynebacterial phospholipids were distinguished by the presence of branched chain isomers of medium chain length. The importance of phospholipids in the taxonomy of the actinomycetes and related eubacteria is discussed.

\section{INTRODUCTION}

The close phylogenetic relationship of mycobacteria, corynebacteria, propionibacteria and nocardia (1) is supported by morphological (2) and immunological evidence (3). For certain members of these genera, the relationship is also shown by studies on the infrared absorption spectra of whole cells (4), by the presence of complex $\alpha$-branched $\beta$-hydroxylated fatty acids (5) attached to either trehalose (6), glucose (7) or cell-wall arabinose (8), and the presence of large amounts of free trehalose (9) and a typical cell wall mucopeptide (10). Moreover, there is evidence that some corynebacteria contain mannophosphoinositides $(11,12)$ previously thought to be restricted to the mycobacteria. In the present work we are concerned with this latter relationship.

\footnotetext{
1 Present address: Department of Biological Chemistry, Medical School, University of Michigan, Ann Arbor, Michigan, 48104.
}

The wide spectrum of phosphoinositides of mycobacteria have been extensively examined by Ballou and coworkers. They range from the simplest lipid, 1-phosphatidyl-L-myoinositol, through those with from one to six molecules of mannose glycosylated to the myoinositol ring (13). The predominant component contains two mannose units (14) and was regarded as 1-phosphatidyl-L-myoinositol 2,6-di-O- $\alpha$-Dmannopyranoside. However, this dimannoside is now known to exist in several acylated forms, the major ones containing two, three and four molecules of fatty acid $(15,16)$.

Previously the morphological relationships between the propionibacteria and mycobacteria were discussed and their close relationship was substantiated by the findings of a monomannophosphoinositide, and an enzyme system for its biosynthesis in propionibacteria (17). However, it was later shown that the bulk of the mannose-inositol-containing lipids of propionibacteria were not glycerides and that the monomannophosphoinositide was a minor component $(18,19)$. In view of the relationship between propionibacteria and corynebacteria (1) it was therefore possible that the mannoseinositol lipids of the latter were not mannophosphoinositides but mannoinositides, a possibility we have excluded in this work.

Some of these results have been published in preliminary form $(20,21)$.

\section{MATERIALS AND METHODS}

\section{Organisms}

Corynebacterium diphtheriae, Corynebacterium equi and Corynebacterium xerosis were obtained from the Department of Bacteriology, Trinity College, Dublin, and were grown, harvested and washed as described previously (7). The origins of Corynebacterium ovis have been described by Carne et al. (22).

\section{Lipid Extraction}

In the early stages of this work the cells were first extracted several times with redistilled acetone. This treatment removed acylglucoses (7); phospholipids were then obtained by subsequent extraction of the bacterial residue with chloroform-methanol-water $(16: 6: 1$, all ratios are by volume). In later experiments cells were extracted only with chloroform-methanolwater. Lipid extracts were washed (23), dried 
by rotary evaporation and stored under nitrogen at 4 C. Prior to column chromatography phospholipid mixtures were emulsified, a small amount of sodium EDTA was added and the emulsion was stored at $4 \mathrm{C}$ for two days. The preparation was then dialyzed against $0.1 \mathrm{M}$ sodium EDTA for $24 \mathrm{hr}$ and against deionized water for a further $24 \mathrm{hr}$. Finally the material was lyophylized and chromatographed. In the case of $C$. ovis, soluble lipids were repeatedly triturated with acetone. Acetone-insoluble lipids only were further examined.

\section{Chromatographic Procedures}

Total lipid extracts were applied to a column of silicic acid (Mallinckrodt) which was eluted first with 2-3 column volumes of chloroform, followed by varying concentrations of acetone in chloroform to remove acylglucoses and acyltrehaloses (7). Phospholipids were then eluted with chloroform-methanol (1:1).

Column chromatography of the phospholipids of $C$. diphtheriae was carried out on DEAE-cellulose (Whatman DE-32) (acetate form) in chloroform-methanol-water (20:9:1) with ammonium acetate gradients (16). Collected fractions $(3 \mathrm{ml})$ were monitored for carbohydrate and phosphorus. Mixed fractions were dialyzed to remove ammonium acetate and chromatographed on thin layer plates. Such lipids were also hydrolyzed or deacylated and the products chromatographed on paper.

Deacylated phospholipids of $C$. ovis were chromatographed on a column of DEAE-Sephadex (14). The column was eluted first with water, followed by a gradient of ammonium carbonate $(0.3 .0 \mathrm{M})$. Ammonium carbonate was removed from eluates by repeated lyophylization and fractions were further purified by passage through a column of Sephadex G-25.

Thin layer chromatography (TLC) of phospholipids was performed on plates $(20 \times 20 \mathrm{~cm}$ and $20 \times 40 \mathrm{~cm}$ ) of Silica Gel $\mathrm{H}$ (Merck). The following solvent systems were used: chloroform-methanol-water $(65: 25: 4)$ (solvent $\mathrm{A}$ ); chloroform-methanol-acetic acid-water (30:15:4:2) (solvent B); chloroform-methanol$7 \mathrm{~N}$ ammonia (12:7:1) (solvent $\mathrm{C}$ ). Lipids were located by exposing the plates to iodine vapor and also by gentle spraying of the plates with water. Carbohydrate-containing lipids were detected with a spray composed of $1 \%$ phenol in $60 \%$ orthophosphoric acid. Phospholipids were detected with the molybdenum-blue reagent (24). A ninhydrin spray was also used for this purpose. In preparative TLC, phospholipids were located by spraying a strip with molybdenum blue reagent or the whole plate with water, bands were scraped from the plates and the lipids eluted from the gel with chloroform-methanol $(1: 2)$ and chloroform-methanol (2:1). Eluted lipids were dried by rotary evaporation and washed (23).

Paper chromatography was performed on Whatman No. 1 or $3 \mathrm{MM}$ paper, using the following solvent systems: Ethyl acetate-acetic acid-formfc acid-water (18:3:1:4) (solvent D); ethyl acetate-pyridine-water (2:1:2, upper phase) (solvent E); isopropyl alcohol-ammoniawater $(7: 1: 2)$ (solvent F). Solvent D proved to be the only one which could effectively resolve glucose, mannose and arabinose. Solvent E was capable of separating mannose and arabinose. Solvent $F$ was used for the separation of glyceryl-phosphoryl derivatives. Separated products were located by staining the papers with the silver nitrate-sodium hydroxide dip reagent (25), the periodate-benzidine dip reagent (26) or the aniline-phthalate spray (27).

Gas liquid chromatography (GLC) of methylated fatty acids was carried out on a Pye Unicam Series 104 Analyzer, using a column of $10 \%$ diethylglycolsuccinate (DEGS) on Chromosorb W, (100/120 mesh). Assignments for each peak were obtained from a semi-logarithmic plot of relative retention times against chain length and degree of unsaturation of standard mixtures of fatty acid methyl esters. The percentage of each acid was estimated from the ratio of the weight of a peak tracing to total weights of all peaks.

\section{Analytical Methods}

Carbohydrates were estimated by a phenol$\mathrm{H}_{2} \mathrm{SO}_{4}$ assay method (28). Total phosphorus was determined by the method of Bartlett (29) and amino compounds by the method of Spies (30). Glycerol was estimated by the amount of formaldehyde produced on periodate oxidation (31). Acid hydrolysis of lipids was carried out with $2 \mathrm{~N} \mathrm{HCl}$ for $3 \mathrm{hr}$ at $100 \mathrm{C}$ in sealed tubes. Lipids were deacylated by mild $\mathrm{NaOH}$ treatment. Methyl esters of fatty acids were obtained either by transmethylation or by saponification followed by methylation with diazomethane.

\section{Materials}

Phosphatidylinositol, phosphatidylethanolamine and phosphatidylserine were isolated from yeast $(32,33)$. Dimannophosphoinositides were isolated from Mycobacterium phlei $(16,34)$. Straight chain and branched chain fatty acids for GLC were obtained from Applied Science Laboratories, State College, $\mathrm{Pa}$. 


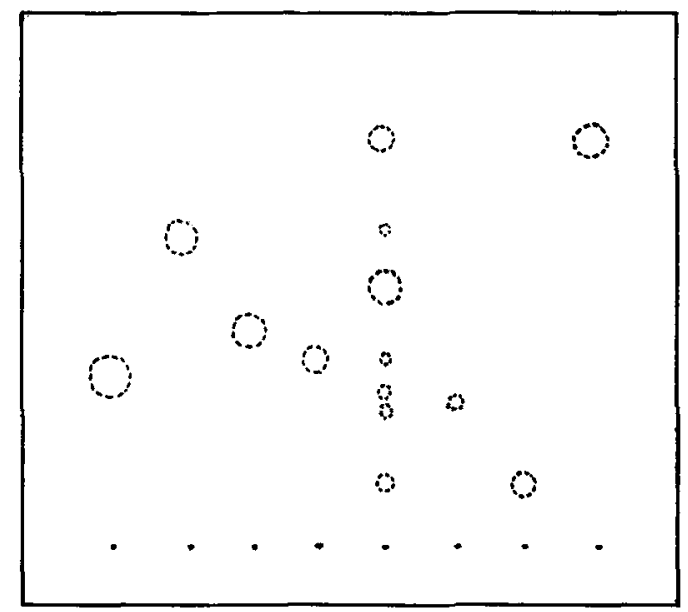

$\begin{array}{lllllll}2 & 3 & 4 & 5 & 6 & 7 & 8\end{array}$

FIG. 1. Thin layer chromatogram of the total phospholipid fraction from Corynebacterium diphtheriae, developed with chloroform-methanol-water $(65: 25: 4)$ and sprayed with the molybdenum blue reagent. 1, phosphatidylinositol; 2 , phosphatidylethanolamine; 3 , dimannophosphoinositide $A ; 4$, phosphatidylserine; 5 , total phospholipid from $C$. diphtheriae; 6 , dimannophosphoinositide $B ; 7$, dimannophosphoinositide $C ; 8$, cardiolipin. (Phospholipids 2-4 were included as markers, but, as mentioned in text, they were absent from $C$. diphtheriae.)

\section{RESULTS}

\section{Phospholipids of Corynebacterium diphtheriae}

Acid hydrolysis of total free lipid of $C$. diphtheriae and chromatography in solvent $\mathrm{D}$ showed mainly glycerol, mannose, glucose and inositol. Ethanolamine and serine were absent from chromatograms stained with ninhydrin. Chromatography of the deacylated lipid in solvent $F$ showed glucose, trehalose, glycerylphosphorylinositol, glycerylphosphorylinositol dimannoside, and an unknown of $R_{\text {glucose }}$ 0.71. [A photograph of the products obtained has previously been published (7) in connection with the identification of acylglucoses in $C$. diphtheriae.] Glucose arose from acylglucose (7). Trehalose was probably due th the presence of diacyltrehalose (cord factor) (6). The origins of the glycerylphosphorylinositol and the glycerylphosphorylinositol dimannoside were investigated further by TLC in solvents $A$ and B. Plates were sequentially visualized with iodine, ninhydrin and the molybdenum blue reagent. Ninhydrin positive lipids were absent as reported previously for $C$. exerosis (20), thus excluding the possible presence of phosphatidylethanolamine or phosphatidylserine in $C$. diphtheriae. The molybdenum blue reagent showed the presence of several phospholipids

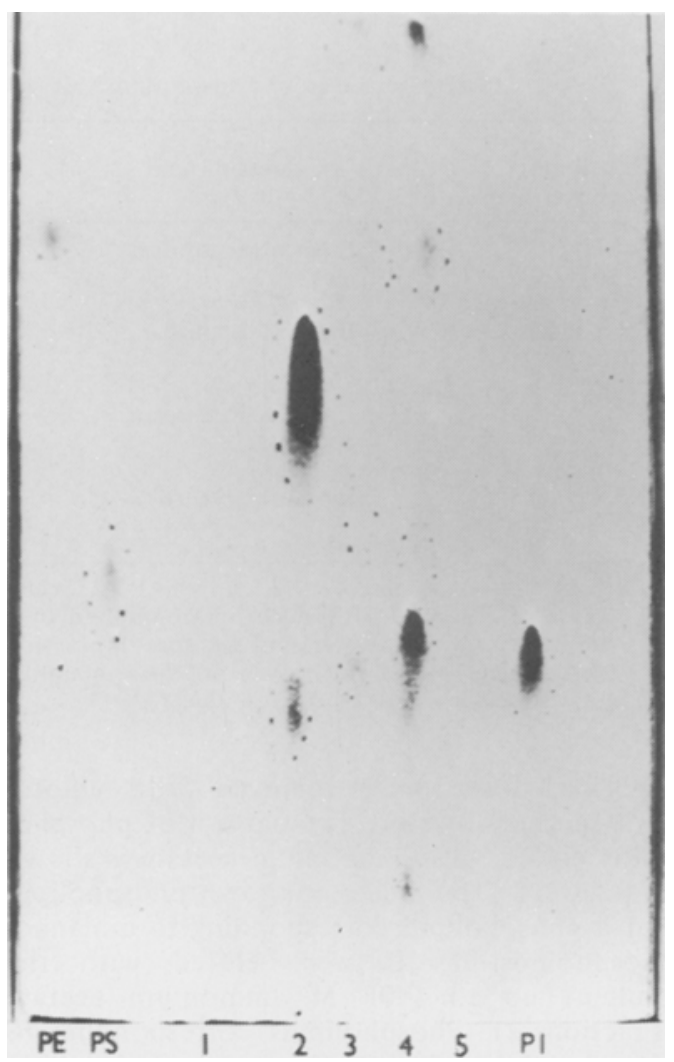

FIG. 2. Thin layer chromatogram of the Corynebacterium diphtheriae phospholipid fractions eluted from the DEAE-cellulose column. PE, phosphatidylethanolamine; PS, phosphatidylserine; 1 , early elutes from the column; 2 , phospholipids eluted with $0.05 \mathrm{M}$ ammonium acetate; $3,4,5$, material eluted with higher concentrations of ammonium acetate; PI, phosphatidylinositol. Chromatography was carried out on long $(40 \mathrm{~cm})$ plates of Silica $\mathrm{Gel} \mathrm{H}$ in chloroformmethanol-water $(65: 25 ; 4)$. Dimannophosphoinositide $C^{\prime}$ (Table II) is not obvious on this photograph. Dotted areas contained lipids which reacted with iodine previous to visualization with the phosphate spray.

(Fig. 1). The major lipid $\left(\mathrm{R}_{\mathrm{f}}[0.56\right.$ in solvent $\mathrm{A})$ is considered later. Another phospholipid had a $R_{f}$ of 0.42 close to that of phosphatidylinositol. Two further phospholipids chromatographed to the same region $\left(R_{f} 0.35\right)$ as the triacylated dimannophosphoinositide B. Other prominent phospholipids corresponding to the diacylated dimannophosphoinositide C from $M$. phlei (16) and to cardiolipin from $M$. tuberculosis.

To purify and further identify the individual phospholipids, lyophilyzed lipid was applied to a column of DEAE-cellulose and eluted as described. Acylglucoses and the traces of 
TABLE I

Characterization of Phosphoinositides Isolated From Corynebacterium diphtheriae

\begin{tabular}{|c|c|c|c|}
\hline $\begin{array}{l}\mathrm{R}_{\mathrm{f}} \text { value of } \\
\text { lipid in } \\
\text { solvent } \mathrm{A}\end{array}$ & $\begin{array}{l}\text { Products of acid } \\
\text { hydrolysis }\end{array}$ & $\begin{array}{l}\text { Products of } \\
\text { deacylation }\end{array}$ & $\begin{array}{c}\text { Probable identity } \\
\text { of lipid }\end{array}$ \\
\hline 0.13 & $\begin{array}{l}\text { Inositol, mannose, } \\
\text { gly cerol }\end{array}$ & $\begin{array}{l}\text { Glycerylphosphoryl- } \\
\text { inositol dimannoside }\end{array}$ & $\begin{array}{l}\text { Diacyl dimannophos- } \\
\text { phoinositide C }\end{array}$ \\
\hline 0.25 & $\begin{array}{l}\text { Inositol, mannose, } \\
\text { glycerol }\end{array}$ & $\begin{array}{l}\text { Glycerylphosphoryl- } \\
\text { inositol dimannoside }\end{array}$ & $\begin{array}{l}\text { Diacyl dimannophos- } \\
\text { phoinositide } C^{\prime}\end{array}$ \\
\hline 0.32 & $\begin{array}{l}\text { Inositol, mannose, } \\
\text { gly cerol }\end{array}$ & $\begin{array}{l}\text { Glycerylphosphoryl- } \\
\text { inositol dimannoside }\end{array}$ & $\begin{array}{l}\text { Triacyl dimannophos- } \\
\text { phoinositide B }\end{array}$ \\
\hline 0.34 & Inositol, glycerol & $\begin{array}{l}\text { Glycerylphosphoryl- } \\
\text { inositol }\end{array}$ & $\begin{array}{l}\text { Phosphatidyl- } \\
\text { inositol }\end{array}$ \\
\hline
\end{tabular}

\footnotetext{
${ }^{\text {a}}$ Fractions 3 and 4 (Fig. 2) from DEAE-cellulose column were applied as bands to long $(40 \mathrm{~cm})$ plates of silica gel $\mathrm{H}$ and chromatographed in chloroform-methanol-water $(65: 25: 4)$. Phospholipids were located with water and by spraying a side strip with molybdenum blue. Chromatography on these longer plates fully resolved the dimannophosphoinositides $B$ and $C^{\prime}$ which chromatographed close together on $20 \mathrm{~cm}$ plates (Fig. 1).
}

diacyltrehaloses were removed with chloroform-methanol-water. The pattern of phospholipids eluted with ammonium acetate is shown in Figure 2. The major unknown phospholipid and a phospholipid corresponding to dimannophosphoinositide $B$ were eluted with the gradient up to $0.05 \mathrm{M}$ ammonium acetate (Fraction 2). Phospholipids corresponding to phosphatidylinositol, dimannophosphoinositide $B$, dimannophosphoinositide $\mathrm{C}$ and some unknowns were subsequently eluted (Fractions 3 and 4). The two phospholipids in Fraction 2 were isolated by preparative TLC in solvent A. The minor one on deacylation yielded glycerylphosphorylinositol dimannoside and hydrolysis showed mannose, glycerol and inositol only. Its $\mathbf{R}_{\mathbf{f}}$ value would indicate the triacylated dimannophosphoinositide B (16). The major lipid in this fraction was the predominant single phospholipid in $C$. diphtheriae. This was repurified twice in solvent $B$; such purifications yielded a nitrogen-free phospholipid. Acid hydrolysis of the lipid followed by paper chromatography and visualization with the silver nitrate-sodium hydroxide reagents showed glycerol only. Assay for glycerol and phosphorus gave a molar ratio of $1.85: 1$. In three solvents the lipid was chromatographically similar to phosphatidylglycerol. It had the following $\mathrm{R}_{\text {phosphatidyl- }}$ ethanolamine values: 0.78 in solvent $\mathrm{A}, 0.90$ in solvent $B$ and 1.10 in solvent $C$. Paper chromatography of the deacylated lipid in solvent $\mathbf{F}$ showed a product with an $\mathrm{R}_{\text {gly cerylphos- }}$ phorylinositol value of 1.66 compared to 1.68 for glycerylphosphorylglycerol. Positive identification of this lipid was not obtained, but the above evidence is strongly indicative of phos- phatidylglycerol.

Four phospholipids were isolated from Fractions 3 and 4 by preparative TLC in solvent A. Identification of these is summarized in Table I. A number of dimannophosphoinositides are obviously present as well as phosphatidylinositol.

\section{Phospholipids of Corynebacterium xerosis, \\ Corynebacterium equi and Corynebacterium ovis}

Brennan (20) previously examined the phospholipids of $C$. xerosis and described the major components, a phosphoinositide and a dimannophosphoinositide. In the present work the organism was re-examined for the possible presence of phosphatidylglycerol and other dimannophosphoinositides. Six phospholipids were isolated by preparative TLC in solvent $A$. The principal ones were identical to the dimannophosphoinositide and phosphoinositide described before (20). Another prominent phospholipid was present with chromatographic properties identical to dimannophosphoinositide $\mathrm{C}$ from $M$. phlei and on deacylation yielded glycerylphosphorylinositol dimannoside. Hydrolysis produced only inositol, mannose and glycerol. Two further phospholipids $\left(R_{f} 0.76\right.$ and $R_{f} 0.94$ in solvent $\left.A\right)$ have not been fully identified. The former on hydrolysis yielded glycerol, glucose and inositol. The latter had chromatographic properties identical to cardiolipin.

The products of acid hydrolysis of the total soluble lipid from $C$. equi were glycerol, mannose, inositol, glucose and arabinose. The major products of deacylation were identified as glycerylphosphorylinositol dimannoside, 
glycerylphosphorylinositol, glycerol and glucose. A prominent product had an $\mathrm{R}_{\text {glucose }}$ value of 0.70 , similar to the glycerylphosphorylglycerol characterized above.

Hydrolysis of the acetone insoluble lipids of $C$. ovis yielded glycerol, glucose, arabinose, mannose and inositol. A portion $(1.03 \mathrm{~g})$ of this material was deacylated, yielding $268 \mathrm{mg}$ of water soluble products. These were fractionated on a column of DEAE-Sephadex and identified by chromatography in solvent $H$. The products were glycerol, arabinose, trehalose, glycerylphosphorylinositol and glycerylphosphorylinositol dimannoside. Since Lacave et al. (35) reported the presence in this organism of phospholipids containing inositol and arabinose, it was possible that we had a glycerylphosphorylinositol diarabinoside instead of the dimannoside. This material was therefore further examined. It was first purified on a column of Sephadex G-25 and rechromatographed in several systems where it had chromatographic properties identical to glycerylphosphorylinositol dimannoside. The deacylated phospholipid was hydrolyzed and chromatographed in solvents $\mathrm{D}$ and $\mathrm{E}$ for long periods to resolve arabinose and mannose. Glycerol was lost from the end of these chromatograms; however, they showed the presence of both inositol and mannose and not arabinose (Fig. 3). Moreover, staining the chromatogram with anilinephthalate showed that the monosaccharide yielded a brown color, characteristic of hexoses and not the purple color of pentoses. Thus, this lipid which is prominent in $C$. ovis, is a dimannophosphoinositide and not a diarabinophosphoinositide.

\section{Fatty Acids of the Phospholipids of Corynebacteria}

TLC in benzene (36) of the methylated phospholipid fatty acids from $C$. diphtheriae, $C$. xerosis and $C$. equi showed they were nonhydroxylated, i.e., they had an $\mathrm{R}_{\mathrm{f}}$ similar to methyl stearate. On the other hand, the methylateu fatty acids from the acetone insoluble lipids of $C$. ovis were seen to contain considerable material with the chromatographic properties of methyl mycolate. This is in agreement with the finding of corynomycolic acid in a similar fraction by Lacave et al. (35) which probably arises from dicorynomycolyltrehalose (6). The methylated phospholipid fatty acids of $C$. ovis and $C$. equi as well as the fatty acids from the four dimannophosphoinositides of $C$. diphtheriae were then examined by GLC (Table II). The major fatty acid of the dimannophosphoinositides of $C$. diphtheriae closely corresponded to $\mathrm{C}_{16: 1}$; in dimannophosphoinositide $B$ it comprised almost half of the total fatty acid content. A feature of these patterns was the prominence of branched chain fatty acid types. The percentage of these ranged from $42.3 \%$ in one sample of dimannophosphoinositide $\mathrm{C}$ to $26.5 \%$ in dimannophosphoinositide B of $C$. diphtheriae. The major type found in all four dimannophosphoinositides was the branched chain $C_{15}$ fatty acid Branched chain fatty acids also predominate in the phospholipids from the other species comprising $66.9 \%$ in $C$. equi and $91.8 \%$ in C. ovis.

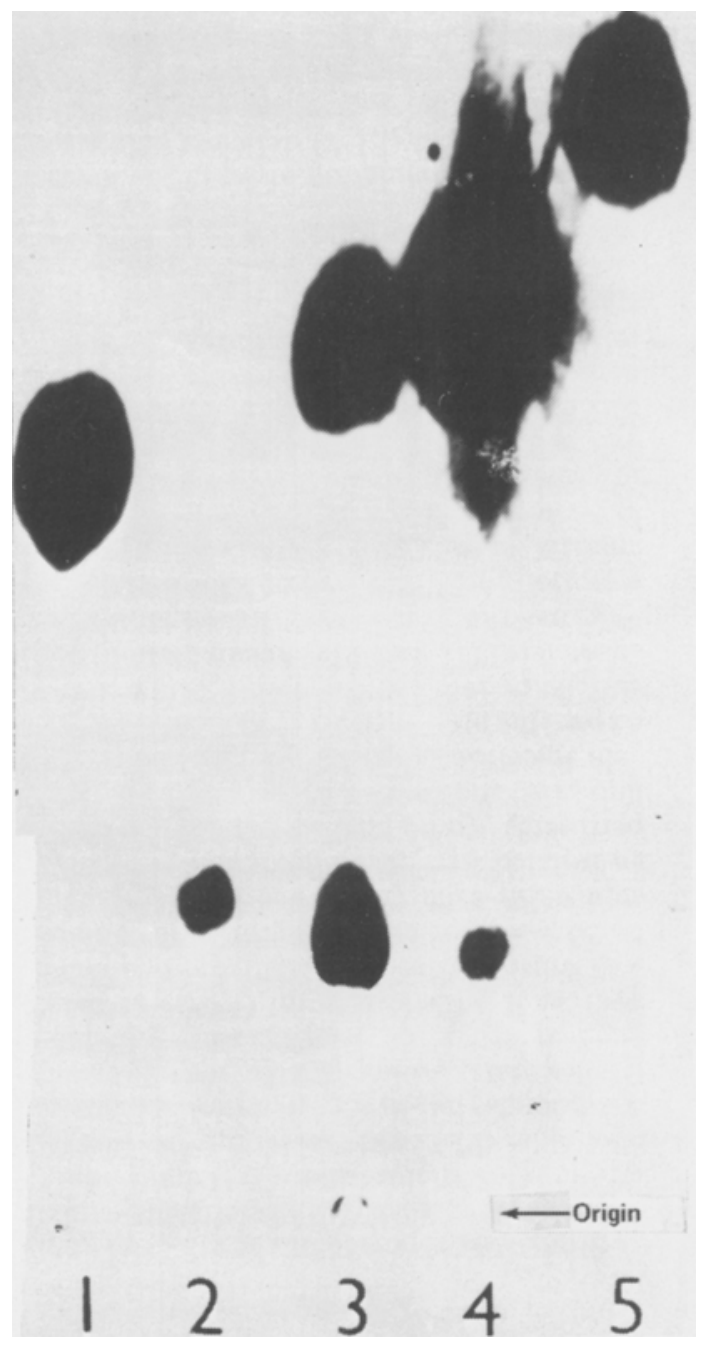

FIG. 3. Hydrolyzed products of deacylated dimannophosphoinositide from Corynebacterium ovis chromatographed in a descending direction in ethyl acetate-acetic acid-formic acid-water $(18: 3: 1: 4)$ and stained with the silver nitrate-sodium hydroxide dip reagent. Glycerol was lost from the end of this chromatogram. 1, glucose; 2, inositol; 3, hydrolyzed products; 4 , mannose and inositol; 5 , arabinose. 


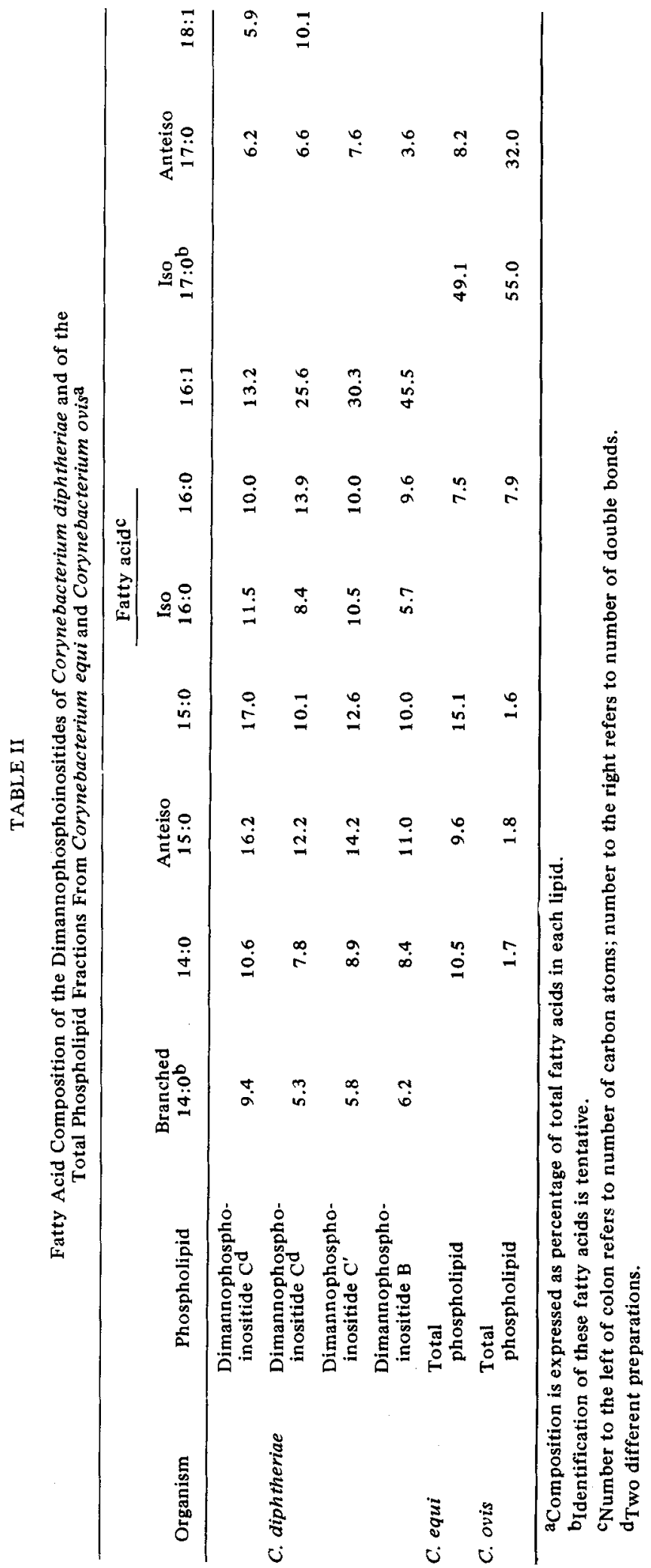


TABLE III

Hypothetical Evolutionary Descent of Mannose-Inositol-Containing Lipids

\begin{tabular}{lll}
\hline \multicolumn{1}{c}{ Genus } & \multicolumn{1}{c}{ Type of lipid } & Reference \\
\hline Propionibacterium & $\begin{array}{l}\text { Monomannoinositide and } \\
\text { monomannophosphoinositide }\end{array}$ & $18,19,17$ \\
Corynebacterium & Dimannophosphoinositides \\
Mycobacterium & $\begin{array}{l}\text { Mono-, di-, tri-, tetra-, } \\
\text { penta- and } \\
\text { hexamannophosphoinositides }\end{array}$ & This work \\
\hline
\end{tabular}

The percentage of saturated straight chain fatty acids varied. They comprised an average of $32 \%$ in the four dimannophosphoinositides of $C$. diphtheriae and $33.1 \%$ in $C$. equi; however in $C$. ovis this figure is reduced to $11.2 \%$. The phospholipids of $C$. ovis and $C$. equi seem to contain most of the fatty acid types present in the dimannophosphoinositides of $C$. diphtheriae, viz. $\mathrm{C}_{14}$, anteiso $\mathrm{C}_{15}, \mathrm{C}_{15}, \mathrm{C}_{16}$ and branched $\mathrm{C}_{17}$; they lack however, branched $\mathrm{C}_{14}$, iso $\mathrm{C}_{16}$ and $\mathrm{C}_{18: 1}$. The most salient point of difference between the phospholipid fractions is, however, that concerning the dominant single isomer in each fraction; in $C$. ovis and $C$. equi, the $\mathrm{C}_{16: 1}$ acids of $C$. diphtheriae appear to be replaced by an iso $\mathrm{C}_{17}$ fatty acid.

\section{DISCUSSION}

The most striking feature of the phospholipids of the corynebacteria examined here is the predominance of phosphoinositide-type lipids, consisting of phosphatidylinositol and dimannophosphoinositides. Unlike mycobacteria, we found no evidence in corynebacteria for mannophosphoinositides other than the dimer. Chromatographic evidence indicated that these dimannophosphoinositides are identical to the triacylated and diacylated dimannophosphoinositides of $M$. phlei but no evidence was found for the tetraacylated dimannophosphoinositide prominent in $M$. phlei and $M$. tuberculosis.

The existence of dimannophosphoinositides in several corynebacteria substantiates the proposed relationship between corynebacteria and mycobacteria. This similarity has received recent fresh support from the computer analyses of corynoform bacteria of Masuo and Nakagawa (37). These authors calculated similarity indices for 12 Gram-positive genera based on phenetic characters as diverse as cell shape and size, stain reactions, cell wall components and nutritionals for growth. Their results showed an overall similarity of approxi- mately $70-75 \%$ between corynebacteria and mycobacteria. The differences found in the composition of the mannophosphoinositides does not detract from the proposed relationship but serves rather to reinforce the existence of corynebacteria as a separate genus.

It is interesting to compare the types of mannoinositides found in the most studied genera, i.e., propionibacteria, corynebacteria and mycobacteria (Table III). Assuming an evolutionary line of descent from monomannoinositides and monomannophosphoinositides to polymannophosphoinositides, the ensuing pathway would match that of Lechevalier and Lechevalier (1). This would also be in agreement with the evolutionary pathway of mycolic acid structure in several of these genera (38). Unfortunately, little is known of the mannosecontaining inositides of the nocardias, but on the basis of their mycolic acid structure they are in an intermediate position between the corynehacteria and mycobacteria.

The phosphoinositides of $C$. ovis represent a special case. Lacave et al. (35) concluded that these were principally arabinophosphoinositides. The fractionation procedure was based on a traditional method largely utilizing the differential solubility of lipids in various organic solvents and does not seem to have been carried out with the ultimate aim of identifying inositol-containing phospholipids. Using more direct procedures, we found two major deacylated phospholipids with chromatographic properties similar to those of glycerylphosphorylinositol and glycerylphosphorylinositol dimannoside. Since the latter compound would be expected to behave chromatographically in a similar fashion to a diarabinoside derivative, the monosaccharides of the compound were examined and shown to be mannose rather than arabinose. This is not to suggest that arabinophosphoinositides do not occur in $C$. avis but that they are probably minor components, possibly on a level with the reported traces of arabinophosphoinositides in $M$. tuberculosis (38). 
The major single phospholipid from $C$. diphtheriae exhibited certain unusual features. Hydrolysis of an apparently pure sample produced one ninhydrin-positive spot in a onedimensional chromatographic system (21). However two-dimensional chromatography showed several amino acids in about equal amounts (D.P. Lehane, unpublished work). Repeated thin layer chromatography of this material finally yielded a preparation free of nitrogen and analyses indicated phosphatidylglycerol. The occurrence of phosphatidylglycerol as the major phospholipid of $C$. diphtheriae seems to represent a point of departure from phylogenetic patterns. Although phosphatidylglycerol is widespread in Gram-positive bacteria (40) it does not appear to be present in appreciable amounts, if at all, in mycobacteria or in nocardia (41); it has however, been reported among the phospholipids of Propionibacterium shermanii (18).

The most prominent feature of the fatty acid patterns of the corynebacterial phospholipids is the predominance of branched chain isomers. In the phospholipids of $C$. diphtheriae, the principal branched chain fatty acid corresponds to anteiso $\mathrm{C}_{15}$, which is in keeping with the finding of Moss et al. (42) that the single most abundant fatty acid in Corynebacterium acnes is a $\mathrm{C}_{15}$ branched chain acid. The range of remaining fatty acids in $C$. diphtheriae is substantially similar to that observed by Moss et al. (42) in C. acnes though differing in relative amounts. The main point of divergence would appear to be that the most abundant single fatty acid present in the phospholipids of $C$. diphtheriae corresponds to $\mathrm{C}_{16: 1}$. The phospholipid fatty acid patterns of C. ovis and C. equi also show large quantities of branched chain fatty acids; however in these organisms the principal isomer would appear to be a branched-chain $\mathrm{C}_{17}$ acid. Although the fatty acids of these organisms are qualitatively similar to those of $C$. diphtheriae, they are quantitatively different. The genus Corynebacterium is composed of a very diverse range of organisms, many of which might be better classified as propionibacteria, or as brevibacteria $(42,43)$. It is not surprising therefore to find different members of this genus with quantitatively distinct fatty acid patterns.

Comparison of the fatty acid patterns of the phospholipids of $C$. diphtheriae with those of the phospholipids of mycobacteria, nocardia and streptomyces $(41,44)$ and with the total fatty acids of listeria (45) reveal overall similarities between the genera. Branched chain fatty acids are prominent, and most straight chain fatty acids from $C_{14}$ to $C_{18}$ are also present. This similarity is most marked between corynebacteria and streptomyces (46) and between corynebacteria and nocardia (47). Between corynebacteria and mycobacteria the major divergence in pattern is found in the fact that the branched chain $\mathrm{C}_{15}$ and $\mathrm{C}_{17}$ fatty acids of the phospholipids of the corynebacteria are replaced in the mycobacteria by the branched $\mathrm{C}_{19}$ fatty acid, tuberculostearic acid (48).

The biological role of the dimannophosphoinositides of corynebacteria is now under consideration in this laboratory. In mycobacteria such lipids are mainly located in the cell envelope and it has been suggested that these lipids are the primary structural components of the cell. The low turnover rate of the mannophosphoinositides supports this hypothesis (49). Shaw and Dinglinger (19) suggest that the hydrophilic portions of the mannoinositides of propionibacteria form pores in the membranes through which small ions and molecules may pass. Such a function may apply to the phosphorylated inositides.

\section{ACKNOWLEDGMENTS}

This work was supported by the National Science Council (Ireland). John Tighe, Miss Ann Slevin and Miss Mairead Kelly assisted. Phosphatidylglycerol from Bacillus cereus was a gift from W.C. Love.

\section{REFERENCES}

1. Lechevalier, H.A., and M.P. Lechevalier, Ann. Rev. Microbiol. 21:71-100 (1967).

2. Prevot, A.R., in "Traite de Systematique Bacterienne," Vol. 2. Dunod, Paris, 1961, p. 771.

3. Castelnuovo, G., G. Belleza, M.E. Duncan and J. Asselineau, Ann. Inst. Pasteur 107:828-844 (1964).

4. Arai, T., S. Kuroda and Y. Koyama, J. Gen. Appl. Microbiol. 9:119-136 (1963).

5. Etemadi, A.-H., These pour le Doctorat de l'Universite de Paris (Mention Medecine), Masson \& Cie., Paris, 1967, p. 84.

6. Senn, M., T. Ioneda, J. Pudles and E. Lederer, Eur. J. Biochem. 1:353-356 (1967).

7. Brennan, P.J., D.P. Lehane and D.W. Thomas, Ibid. 13:117-123 (1970).

8. Kanetsuna, F., Biochim. Biophys. Acta 158:130-143 (1968).

9. Brennan, P.J., Biochem. J. 110:9p (1968).

10. Cummins, C.S., and H. Harris, J. Gen. Microbiol. 28:35-50 (1962).

11. Asselineau, J., Biochim. Biophys. Acta 54:359-360 (1961)

12. Ferreira Gomes, N., T. Ioneda and J. Pudles, Nature 21 1:81-82 (1966).

13. Lee, Y.C., and C.E. Ballou, Biochemistry 4:1395-1404 (1965).

14. Lee, Y.C., and C.E. Ballou, J. Biol. Chem. 239:1316-1327 (1964).

15. Pangborn, M.C., and J.A. McKinney, J. Lipid Res. 7:627-633 (1966)

16. Brennan, P., and C.E. Ballou, J. Biol. Chem. 242:3046-3056 (1967). 
17. Brennan, P., and C.E. Ballou, Biochem. Biophys. Res. Commun. 30:69-75 (1968).

18. Prottey, C., and C.E. Ballou, J. Biol. Chem. 243:61 96-6204 (1968).

19. Shaw, N., and F. Dinglinger, Biochem. J. 112:769-775 (1969).

20. Brennan, P.J., Ibid. 109:158-160 (1968).

21. Brennan, P.J., and D.P. Lehane, Ibid. $115: 8 \mathrm{p}$ (1969)

22. Carne, H.R., N. Wickham and J.C. Kater, Nature 178:701-702 (1956)

23. Folch, J., M. Lees and G.H. Sloane Stanley, J. Biol. Chem. 226:497-509 (1957).

24. Dittmer, J.C., and R.L. Lester, J. Lipid Res. 5:126-127 (1964).

25. Anet, E.F.L.J., and T.M. Reynolds, Nature 174:930 (1954).

26. Gordon, H.T., W. Thornburg and L.N. Werum, Anal. Chem. 28:849-855 (1956).

27. Partridge, S.M., Nature 164:443 (1949).

28. Hough, L., and J.K.N. Jones, "Methods in Carbohydrate Chemistry," Vol. 1, Academic Press, Inc., New York, 1962, p.21.

29. Bartlett, G.R., J. Biol. Chem. 234:466-468 (1959).

30. Spies, J.R., "Methods in Enzymology," Vol. 3, Academic Press, Inc., New York, 1957, p. 468.

31. Renkonen, O., Biochim. Biophys. Acta $56: 367-369$ (1962)

32. Letters, R., Ibid. 116:489-499 (1966).

33. Trevelyan, W.E., J. Lipid Res. 7:445-447 (1966).

34. Brennan, P., and C.E. Ballou, J. Biol. Chem.
$243: 2975-2984$ (1968).

35. Lacave, C., J. Asselineau and R. Toubiana, Eur, J. Biochem. 2:37-43 (1967)

36. Morrison, W.R., and L.M. Smith, J. Lipid Res. 5: 600-608 (1964).

37. Masuo, E., and T. Nakagawa, Agr. Biol. Chem. 33:1124-1129 (1969).

38. Etamadi, A.-H., Bull. Soc. Bot. Fr 1965:47-74.

39. Nojima, S., J. Biochem. 46:607-611 (1959).

40. Macfarlane, M.G., "Advances in Lipid Research," Vol. 2, Academic Press Inc., New York, 1964, p. 91.

41. Yano, I., Y. Furukawa and M. Kusunose, J. Bact. 98:124-130 (1969).

42. Moss, C.W., V.R. Dowell, Jr., V.J. Lewis and M.A. Schekter, Ibid. 94:1300-1305 (1967).

43. Leifson, E., Bact. Rev, 30:257-266 (1966).

44. Kataoka, T., and S. Nojima, Biochim. Biophys. Acta 144:681-683 (1967).

45. Raines, L.J., C.W. Moss, D. Farshtchi and B. Pittman, J. Bact. 96:2175-2177 (1968).

46. Ballio, A., S. Barcellona and L. Boniforti, Biochem. J. 94:11-13c (1965).

47. Bordet, C., and G. Michel, Biochim. Biophys. Acta 70:61 3-626 (1963).

48. Asselineau, J., "The Bacterial Lipids," Holden Day Inc., San Francisco, 1966, p. 243.

49. Akamatsu, Y., Y. Ono and S. Nojima, J. Biochem. 61:96-102 (1967).

[Received November 23, 1970] 